\title{
Synthesis of a Novel Ce-bpdc for the Effective Removal of Fluoride from Aqueous Solution
}

\author{
Changqing Zhao, ${ }^{1}$ Yanwei Cui, ${ }^{1}$ Fang Fang, ${ }^{1}$ Si Ok Ryu, ${ }^{2}$ and Jiarui Huang ${ }^{1}$ \\ ${ }^{1}$ College of Chemistry and Materials Science, Center for Nano Science and Technology, Anhui Normal University, \\ Wuhu, Anhui 241000, China \\ ${ }^{2}$ School of Chemical Engineering, Yeungnam University, Gyeongsan, Gyeongbuk 712749, Republic of Korea
}

Correspondence should be addressed to Si Ok Ryu; soryu@ynu.ac.kr and Jiarui Huang; jrhuang@mail.ahnu.edu.cn

Received 5 March 2017; Accepted 15 May 2017; Published 12 June 2017

Academic Editor: Sergio E. Ulloa

Copyright (c) 2017 Changqing Zhao et al. This is an open access article distributed under the Creative Commons Attribution License, which permits unrestricted use, distribution, and reproduction in any medium, provided the original work is properly cited.

Ce-1,1'-biphenyl-4,4'-dicarboxylic acid (Ce-bpdc), a novel type of metal organic framework, was synthesized and applied to remove excessive fluoride from water. The structure and morphology of Ce-bpdc were measured by X-ray diffraction, scanning electron microscopy, Fourier transform infrared spectroscopy, and X-ray photoelectron spectroscopy. The effects, such as saturated adsorption capacity, $\mathrm{HCO}_{3}{ }^{-}$, and $\mathrm{pH}$, were investigated. The optimal $\mathrm{pH}$ value for fluoride adsorption was the range from 5 to 6 . The coexisting bicarbonate anions have a little influence on fluoride removal. The fluoride adsorption over the Ce-bpdc adsorbent could reach its equilibrium in about $20 \mathrm{~min}$. The Ce-bpdc coordination complex exhibited high binding capacity for fluoride ions. The maximum adsorption capacity calculated from Langmuir model was high up to $45.5 \mathrm{mg} / \mathrm{g}$ at $298 \mathrm{~K}$ ( $\mathrm{pH}=7.0$ ) and the removal efficiency was greater than $80 \%$. In order to investigate the mechanism of fluoride removal, various adsorption isotherms such as Langmuir and Freundlich were fitted. The experimental data revealed that the Langmuir isotherm gave a more satisfactory fit for fluoride removal. Finally, the tested results of ground water samples from three places, Yuefang, Jiangji, and Sanyi which exhibited high removal efficiency, also demonstrate the potential utility of the Ce-bpdc as an effective adsorbent.

\section{Introduction}

Fluoride ions are ubiquitous in surface and underground water and are one of the critical components for dental and bone health of mammals which are found to be beneficial for the mineralization of hard tissues in the mammal body in a narrow concentration with range of $0.5-1.5 \mathrm{mg} / \mathrm{L}$ [1-4], and fluorine and its compounds are valuable and extensively used in industry of fertilizers, high purity graphite, semiconductors, electrolysis of alumina, and so forth [5]. Fluorine ions are found in trace amounts in various tissues of the human body, particularly teeth and bones, where $80 \%-90 \%$ of the fluorine ions in the human body are present. Fluoride ions are also important constituents of bone and teeth; a healthy body requires approximately $1.0 \mathrm{mg}$ of fluorine ions every day. On the other hand, severe side effects, such as bone cancer and fluorosis, can occur when people are exposed to fluoride concentrations in excess of $1.5 \mathrm{mg} / \mathrm{L}$ for long periods $[6,7]$.
Though the presence of fluoride in drinking water is essential for human health, excessive intake of fluoride will result in diseases such as dental, skeletal, or crippling fluorosis in children and fetal cerebral function, neurotransmitters and brain damage, Alzheimer's syndrome, thyroid disorder, and cancer in adults [8-11]. The World Health Organization (WHO) has recommended a guidance value of $1.5 \mathrm{mg} / \mathrm{L}$ for fluoride in drinking water, and the permissible concentration of fluoride ions is less than $1.0 \mathrm{mg} / \mathrm{L}$ in China $[12,13]$. This concern greatly promotes the water community for searching an effective way of defluoridation.

Excess fluoride ions from groundwater for meeting the requirement of drinking water can be removed by various techniques, including ion-exchange [14-16], reverse osmosis $[17,18]$, dialysis and electrodialysis $[19,20]$, precipitation $[21,22]$, membrane separation $[23,24]$, coagulation sedimentation [25], electrocoagulation [26, 27], and adsorption and biosorption [28-30]. In the previous period, the traditional 
method for fluoride removal is to form insoluble salts by adding calcium salt, aluminum salt, or iron salt as precipitant. On the other hand, these classical methods need to add a large amount of precipitate or coprecipitating agent; therefore, these methods are limited because they cannot meet the drinking water standards by the World Health Organization (WHO) [31]. Up to now, several methods are being developed to remove fluoride ions, such as adsorption through the use of metal oxide, metal-loaded synthetic polymer, biopolymer, and some anion exchange resin as efficient defluoridation adsorbents $[32,33]$. Although they have already been modernized or studied by some researchers, these methods are still tedious and time-consuming and have no practical applications [34]. Adsorption is a more acceptable defluoridation method and plays an important role in the purification of water with trace levels of fluoride because of the simplicity of design, environmental considerations, effectiveness, and convenience as compared to other methods [31-34]. Adsorbents with favorable structures, high adsorption capacities, and ease of separation are highly desirable. Among the adsorbents used for defluoridation, such as activated carbon [35], metal oxides [36-38], and aluminum based adsorbents [39, 40], aluminum hydroxides receive more attention because of their strong affinity for fluoride and low cost for large-scale production [41]. In recent years, a variety of adsorbents, like $\mathrm{Ce}(\mathrm{III})$-incorporated cross-linked chitosan, $\mathrm{Zr}(\mathrm{IV})$ immobilized cross-linked chitosan, and so forth, have been identified for the purpose of defluoridation $[9,42]$.

Metal organic frameworks (MOFs) constructed by metalcontaining nodes connected by organic bridges, as potential adsorbents, attract a great deal of interest because of their large surface areas, adjustable pore sizes, and controllable properties, as well as acceptable thermal stability. MOFs can exhibit ultrahigh porosity and high thermal and chemical stability and have been altered for use in various adsorptionrelated areas [43]. Recently, a number of researchers started to investigate the capability of MOFs to remove compounds including removal of metal ions [44-46] and toxic dyes $[47,48]$ in aqueous environment. These studies unveiled the fact that several types of MOFs can remain intact in aqueous solutions and show exceptional capacities to remove pollutants from water compared to traditional adsorbents. Lately, MOFs has also been evaluated for defluoridation in water $[23,49,50]$.

More researchers have focused on rare earth metals, and rare earth element hydrous oxides, for example, cerium and lanthanum and its salts, have strong affinity to fluoride, arsenate, and other anions [51]. Cerium is investigated using first-principles calculations based on density functional theory to stabilize the structural and electronic properties [52]. In our present study, Ce-1,1'-biphenyl-4,4'-dicarboxylic acid (Ce-bpdc), a novel type of metal organic framework and novelly defined adsorption for rapid removal of fluoride from aqueous solution, was prepared for the first time. Ce-MOFs adsorbents were prepared and used for fluoride removal, respectively. Ce-MOFs adsorbents were investigated by X-ray diffraction, scanning electron microscopy, Fourier transform infrared spectroscopy, and X-ray photoelectron spectroscopy. The as-prepared adsorbent was also used for treatment of underground water with high fluoride concentration in Yuefang, Jiangji, and Sanyi in Anhui province of China. Thus, it is desirable to develop low cost adsorbents which can efficiently work in a real sample. The maximum adsorption capacity and removal efficiency were studied and had most crucial part in adsorption. This study indicated that Ce-MOFs membrane could be developed into a very viable technology for highly effective removal of fluoride from drinking water.

\section{Experimental}

2.1. Preparation of Disodium 4,4'-Biphenylenedicarboxylate. All chemicals used in this study were of pure analytical grade and used without further purification. $5.0 \mathrm{~g}$ of $1,1^{\prime}$-biphenyl$4,4^{\prime}$-dicarboxylic acid was dissolved in $80 \mathrm{~mL}$ of water in a $250 \mathrm{~mL}$ beaker with vigorous stirring, and a uniform cloudy solution was obtained. Subsequently, a $10 \mathrm{M} \mathrm{NaOH}$ solution was added dropwise to the above mixed solution with vigorous stirring, until the precipitation disappeared. The mixture solution was then heated and crystallized. The obtained crystals were washed several times with Milli-Q water $(18 \mathrm{M} \Omega)$ to yield the final product, disodium $4,4^{\prime}$ biphenylenedicarboxylate.

2.2. Preparation of Ce-bpdc Coordination Complex. Briefly, $3.0 \mathrm{~g}$ of disodium $4,4^{\prime}$-biphenylenedicarboxylate was placed into a $100 \mathrm{~mL}$ beaker, followed by the addition of an appropriate amount of water for complete dissolution under ultrasonic irradiation. Subsequently, the solution was stirred vigorously with a magnetic agitator. $\mathrm{Ce}\left(\mathrm{NO}_{3}\right)_{3} \cdot 6 \mathrm{H}_{2} \mathrm{O}$ was dissolved in water and added slowly to the above solution, resulting in a turbid solution, which was stirred for $1 \mathrm{~h}$. The resulting precipitate was centrifuged and washed several times with Milli-Q water and vacuum dried at $50^{\circ} \mathrm{C}$ for $24 \mathrm{~h}$.

2.3. Characterization. The products were characterized by X-ray diffraction (XRD, Shimadzu XRD-6000, with high-intensity $\mathrm{Cu} \mathrm{K \alpha}$ radiation with a wavelength of $1.54178 \AA$ ), scanning electron microscopy (SEM, Hitachi S-4800, operated at $5 \mathrm{kV}$ ), and Fourier transform infrared (FT-IR, IRPrestige-21) spectroscopy. X-ray photoelectron spectroscopy (XPS, Thermo ESCALAB 250) was carried out using an Al-K $\alpha 150 \mathrm{~W}$ nonmonochromatized X-ray source and a hemispherical energy analyzer at pass energy of $30 \mathrm{eV}$.

2.4. Detection of Fluoride Ions. The experiments were performed using the fluoride ion-selective electrode method to detect $\mathrm{F}^{-}$. Because the electromotive force of the primary cell consisted of a fluoride ion-selective electrode and $\mathrm{F}^{-}$solution and the logarithm of $\mathrm{F}^{-}$activity had a linear relationship, the electromotive force was measured first, followed by the concentration of the $\mathrm{F}^{-}$solution. The standard curve method was applied to an analysis of the linear relation: a set of different concentrations of standard $\mathrm{F}^{-}$solutions were prepared before the concentration of the testing $\mathrm{F}^{-}$solution was examined. The linear formula could be obtained by checking the electromotive force of the primary cell consisting of an electrode and the standard $\mathrm{F}^{-}$solution. The concentration 


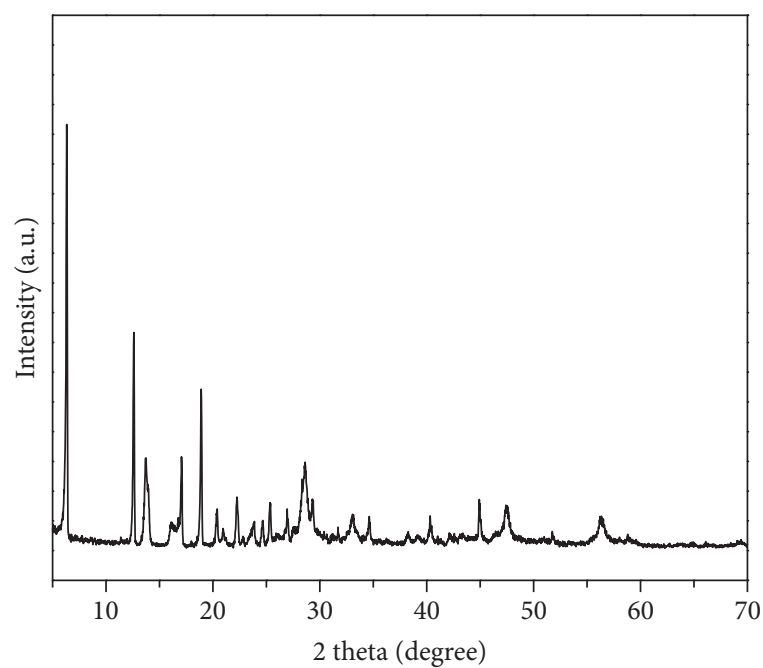

(a)

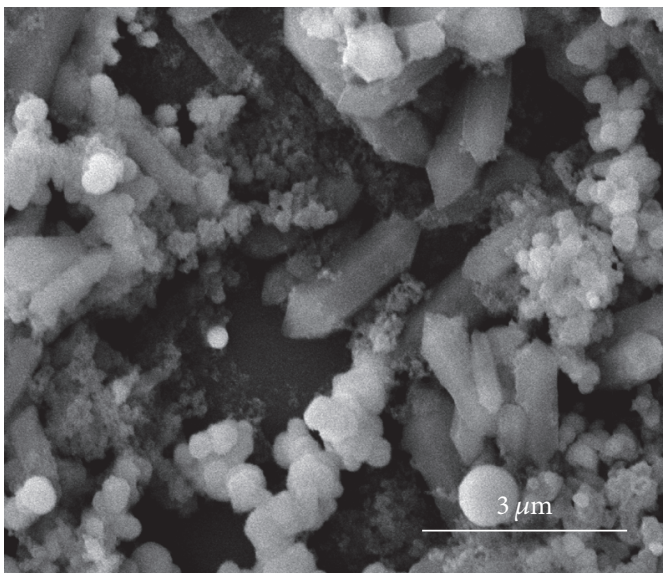

(b)

FIgURE 1: (a) XRD patterns and (b) SEM image of Ce-bpdc.

of the testing $\mathrm{F}^{-}$solution can then be obtained using the linear formula and the electromotive force of the primary cell consisted of electrode and the testing $\mathrm{F}^{-}$solution. The main steps of this method were to immerse the selective electrode into $\mathrm{F}^{-}$and constitute primary cell and measure the electromotive force of the primary cell using $\mathrm{pH}$ meter (model: PHS-3C).

\section{Results and Discussion}

3.1. Structure and Morphology. The crystal phase of the asprepared products was characterized by XRD. As shown in Figure 1(a), the XRD peaks of the Ce-bpdc were sharp and intense, indicating the high crystallinity of the Ce-bpdc, and there was a sharp characteristic peak of M-O at approximately $6^{\circ}$. However, it is hard for us to obtain the Ce-bpdc single crystals and the single crystal structure of the new metal organic compound Ce-bpdc cannot be determined by X-ray single crystal structure analysis. Figure 1(b) presents a SEM image of the sample. The as-prepared Ce-bpdc sample had micrometer-sized rod-like and sphere-like shapes.

FT-IR spectroscopy was used to confirm all the functional groups of Ce-bpdc. The FT-IR spectra of the dried Ce-bpdc and diphenyldicarboxylic acid were investigated, as shown in Figure 2. A comparison of the two spectra revealed a red shift in the spectrum of Ce-bpdc, and the characteristic peaks observed at $1584 \mathrm{~cm}^{-1}$ and $1528 \mathrm{~cm}^{-1}$ were assigned to the COO-Ce. The peak at $3400 \mathrm{~cm}^{-1}$ was ascribed to the $-\mathrm{OH}$ stretching mode in the coordination complex or $\mathrm{H}_{2} \mathrm{O}$ in the sample. The peak at $600-1000 \mathrm{~cm}^{-1}$ was assigned to the atomic vibration of benzene ring.

The surface compositions and chemical states of the asprepared Ce-bpdc were evaluated by XPS. The XPS survey spectrum in Figure 3 indicates the presence of Ce. The peaks at $882.0 \mathrm{eV}, 884.0 \mathrm{eV}$, and $902.0 \mathrm{eV}$ were assigned to $\mathrm{Ce}^{4+}$, Ce $3 d_{5 / 2}$, and Ce $3 d_{3 / 2}$, respectively, which indicates that the

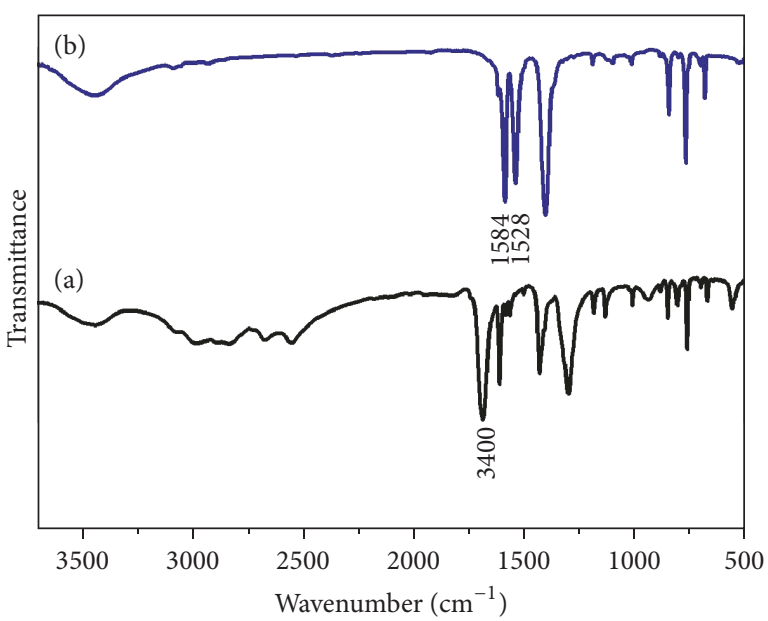

FIgure 2: FT-IR spectra of (a) bpdc and (b) Ce-bpdc.

valence state of the majority of cerium is +3 and also contains a small amount of $\mathrm{Ce}^{4+}$. In the O1s spectrum, the peaks at $531.9 \mathrm{eV}, 532.5 \mathrm{eV}$, and $532.9 \mathrm{eV}$ were assigned to crystal lattice oxygen, and the peak at $533.9 \mathrm{eV}$ was attributed to adsorbing oxygen in the sample. In the Cls spectrum, the peaks at $285.4 \mathrm{eV}, 287.0 \mathrm{eV}$, and $289.0 \mathrm{eV}$ were ascribed to C-OR, C-X, and $\mathrm{MCO}_{3}$, respectively, indicating the presence of $\mathrm{CeCO}_{3}$ in Ce-bpdc.

\subsection{Adsorption Experiments}

3.2.1. Adsorption of $p H$ Dependence. Because $\mathrm{OH}^{-}$and $\mathrm{F}^{-}$are isoelectronic species but $\mathrm{OH}^{-}$is more active than $\mathrm{F}^{-}$, it can compete with $\mathrm{F}^{-}$during the adsorption process [53]. As a result, most of the adsorbent material of $\mathrm{F}^{-}$needs to be used under acidic conditions, which is unavailable for drinking water. Therefore, it is essential to study materials that can 


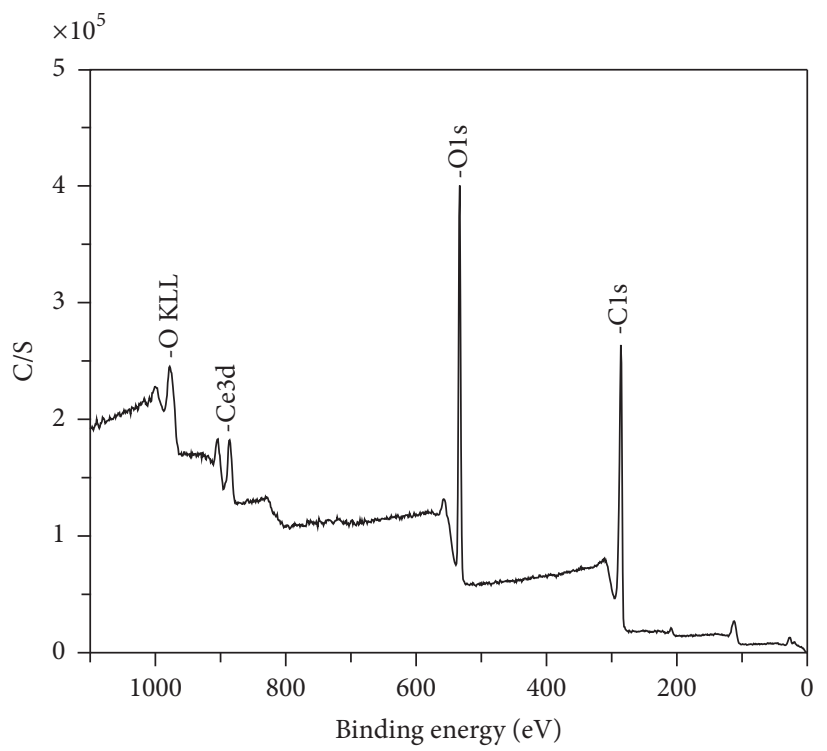

(a)

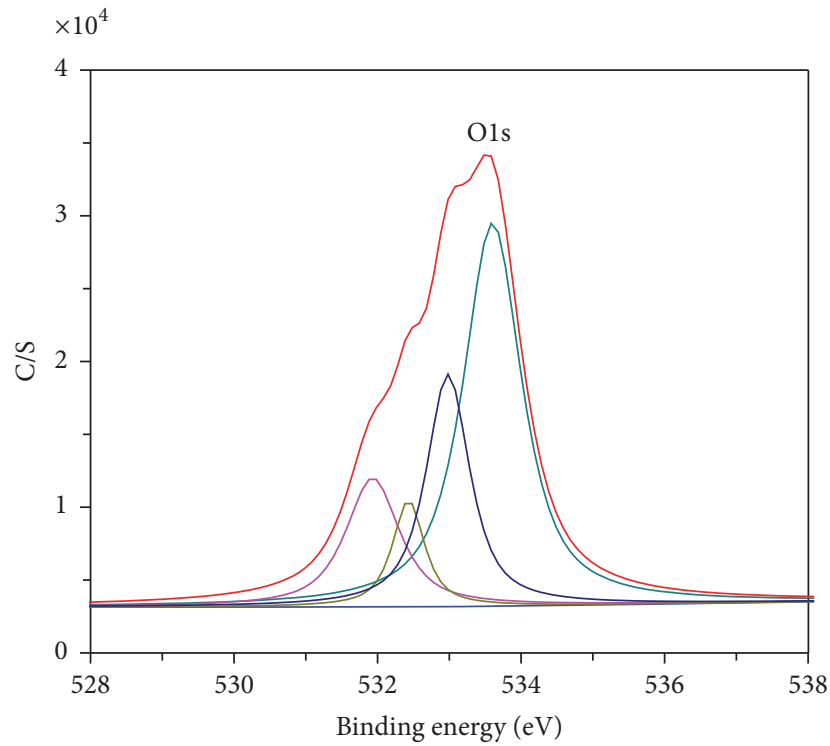

(c)

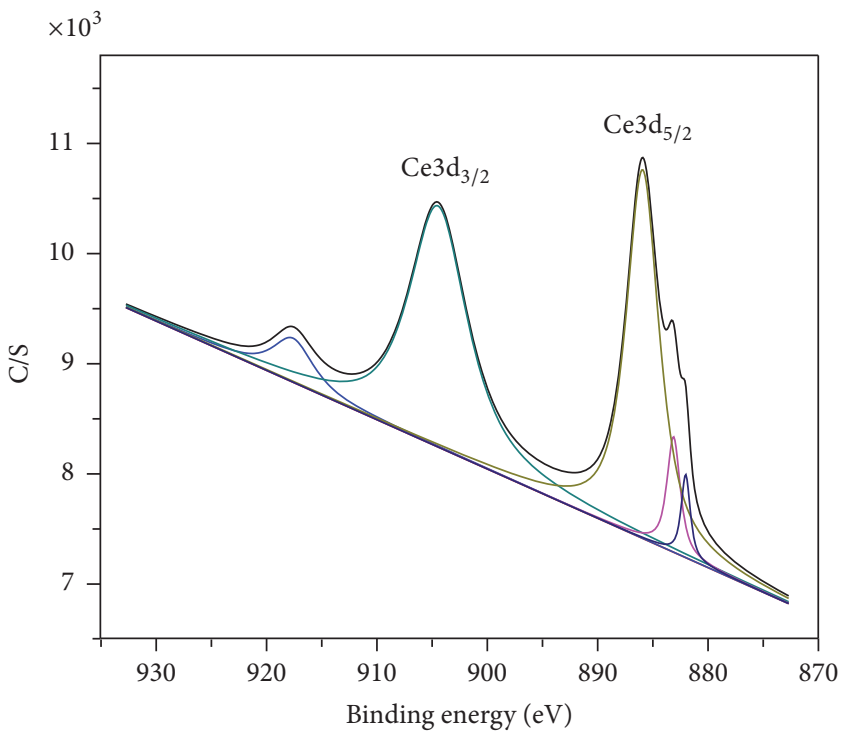

(b)

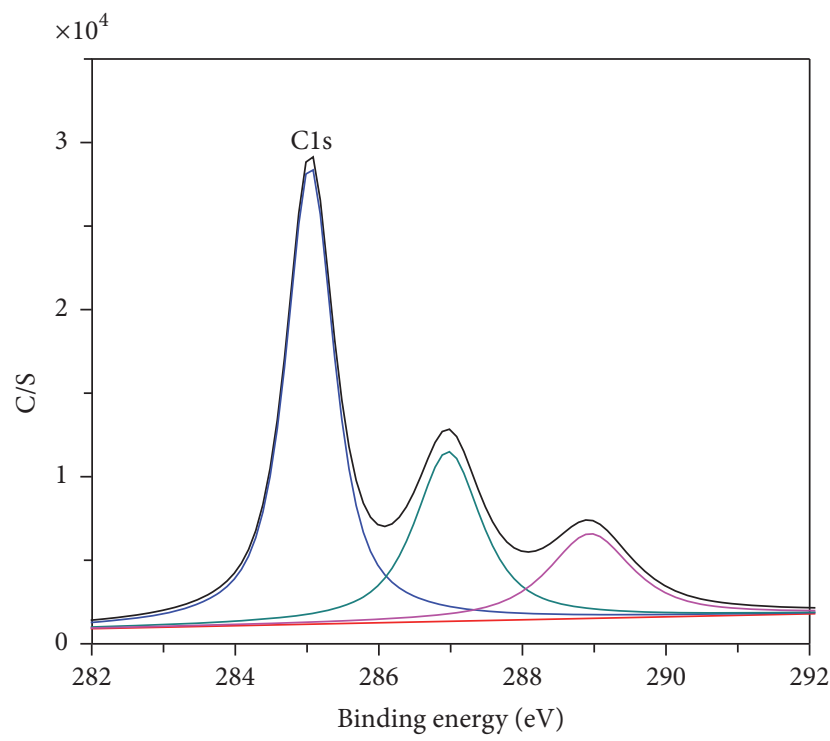

(d)

FIGURE 3: (a) XPS survey spectrum of Ce-bpdc, (b) high-resolution Ce 3d core-level XP spectrum, (c) high-resolution O1s core-level XP spectrum, and (d) high-resolution C1s core-level XP spectrum.

remove $\mathrm{F}^{-}$under neutral solution conditions. In these experiments, the optimal $\mathrm{pH}$ for the removal of $\mathrm{F}^{-}$by Ce-bpdc was examined; the adsorption experiments were performed at $\mathrm{pH}=3.0,4.0,5.0,6.0,7.0$, and 8.0. As shown in Figure 4, when the $\mathrm{pH}$ was increased from 3.0 to 5.0 , the adsorption capacity increased with increasing $\mathrm{pH}$. On the other hand, the adsorption capacity decreased rapidly when the $\mathrm{pH}$ was higher than 6.0. From the above data, Ce-bpdc has the optimal adsorption capacity when the $\mathrm{pH}$ is ca. 6.0. Therefore, all the following experiments were conducted at $\mathrm{pH}=6.0$.

3.2.2. Saturated Adsorption Capacity. The curve of the adsorption capacity of $\mathrm{F}^{-}$with $\mathrm{Ce}$-bpdc changed with various initial concentrations of solution $\mathrm{F}^{-}$. As shown in Figure 5, the adsorption capacity increased with increasing $\mathrm{F}^{-}$concentration. The experimental data was simulated using the Langmuir and Freundlich models, as shown in Figure 5 and Table 1. In Figure 5, the solid line is Langmuir model simulation, and the dashed line is the Freundlich model simulation. From Table 1, the Langmuir model can better represent the data $\left(R^{2}=0.97515\right)$ than the Freundlich model $\left(R^{2}=0.81688\right)$, indicating that the adsorption isotherms fit the Langmuir model. Therefore, the adsorption of $\mathrm{F}^{-}$is due mainly to chemical adsorption with physical adsorption as a complement. The maximum saturation capacity of Ce-bpdc towards $\mathrm{F}^{-}$is $45.5 \mathrm{mg} / \mathrm{g}$. 
TABLE 1: Parameters for the Langmuir and Freundlich models.

\begin{tabular}{lccccc}
\hline & L-model & & \multicolumn{3}{c}{ F-model } \\
$Q_{m}$ & $K_{\mathrm{L}}$ & $R^{2}$ & $n$ & $\ln K_{\mathrm{F}}$ & $R^{2}$ \\
\hline $45.5 \mathrm{mg} / \mathrm{g}$ & 0.2265 & 0.97515 & 1.818 & 2.125 & 0.81688 \\
\hline
\end{tabular}

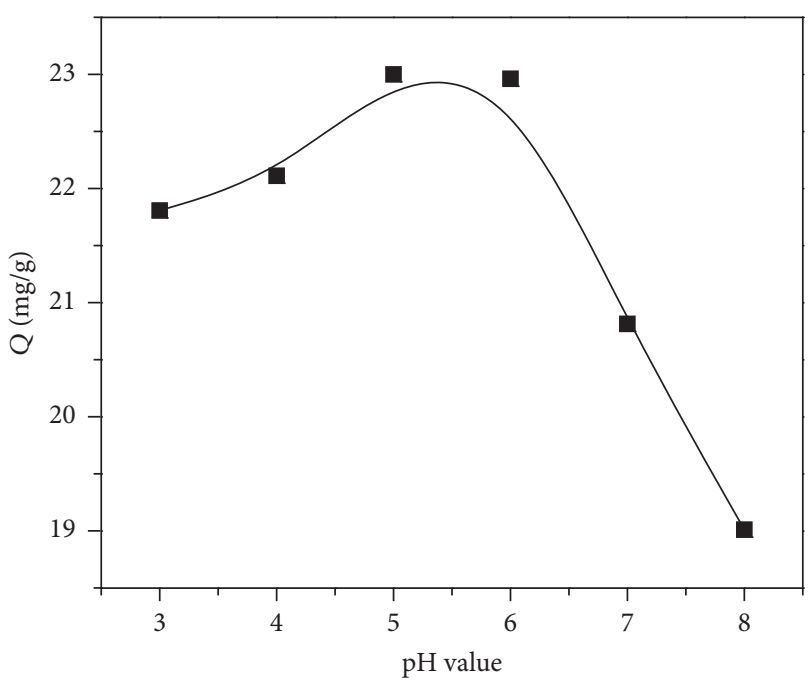

FIGURE 4: Influence of $\mathrm{pH}$ on the adsorption capacity (conditions: adsorption time, $24 \mathrm{~h}$; initial concentration of solution, $24 \mathrm{mg} / \mathrm{L}$; amount of adsorbent, $1.0 \mathrm{~g} / \mathrm{L}$ ).

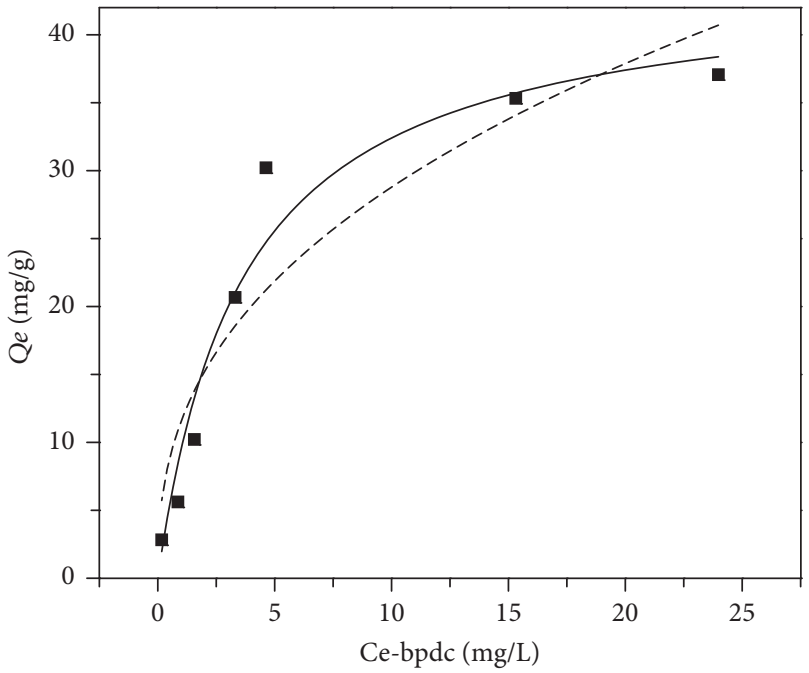

FIGURE 5: Equilibrium adsorption curve (conditions: adsorption time, $24 \mathrm{~h}$; initial concentration of solution, $6-60 \mathrm{mg} / \mathrm{L}$; amount of adsorbent, $1.0 \mathrm{~g} / \mathrm{L} ; \mathrm{pH}=5-6$ ). The solid line is Langmuir model simulation, and the dashed line is Freundlich model simulation.

3.2.3. Removal Efficiency. If an adsorbent has high adsorption capacity, it does not mean that it has high removal efficiency. Therefore, for further analysis of the maximum adsorption capacity, more calculations are needed when the experiments are finished, which can determine if Ce-bpdc can remove fluoride ions from water efficiently. Figure 6 shows that the removal efficiency is greater than $80 \%$ when the $\mathrm{F}^{-}$

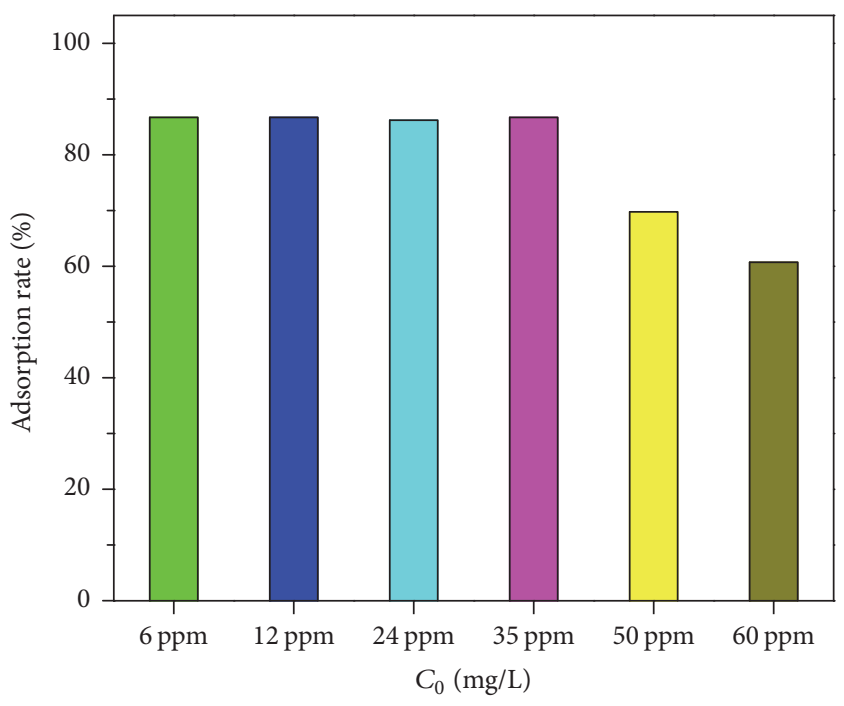

FIGURE 6: Removal efficiency (conditions: adsorption time, $24 \mathrm{~h}$; initial concentration of solution, $6-60 \mathrm{mg} / \mathrm{L}$; amount of adsorbent, $1.0 \mathrm{~g} / \mathrm{L} ; \mathrm{pH}=6)$.

concentration is no more than $35 \mathrm{mg} / \mathrm{L}$. The concentration is below $1 \mathrm{ppm}$ after treatment when the initial concentration of $\mathrm{F}^{-}$is $6 \mathrm{mg} / \mathrm{L}$. This shows that the Ce-bpdc not only has high adsorption capacity but also has high removal efficiency.

3.2.4. Adsorption Kinetics. A kinetic study was performed at $\mathrm{pH}=6$ utilizing a $12 \mathrm{mg} / \mathrm{L} \mathrm{F}^{-}$solution and $1.0 \mathrm{~g} / \mathrm{L}$ adsorbent in a water bath. $8 \mathrm{~mL}$ of the mixed solution was taken out at a certain time. The adsorbent was separated by centrifuge. The concentration of fluoride ions was measured using a fluoride ion-selective electrode. Finally, the adsorption capacities were calculated at different times. Figure 7 shows the adsorption capacities at 2, 5, 10, 15, 20, 30, 60, and $120 \mathrm{~min}$. From Figure 7 , the reaction proceeded rapidly in the first $20 \mathrm{~min}$, after which, the reaction reached equilibrium. A pseudo-second-order rate equation was used to simulate the kinetic adsorption as follows:

$$
\frac{t}{Q_{t}}=\frac{1}{2 K_{2} Q_{e}^{2}}+\frac{t}{Q_{e}}
$$

where $K_{2}(\mathrm{~g} / \mathrm{mg} \cdot \mathrm{h})$ is the pseudo-second-order rate constant of adsorption, $Q_{t}(\mathrm{mg} / \mathrm{g})$ is the amount of $\mathrm{F}^{-}$adsorbed by the adsorbent at time $t(\mathrm{~min})$, and $Q_{e}(\mathrm{mg} / \mathrm{g})$ is the equilibrium adsorption capacity. Figure 7 shows a linear plot of $t / Q_{t}$ versus $t$. The $K_{2}$ value was calculated from the slope and the intercept was $0.067 \mathrm{~g} / \mathrm{mg} \cdot \mathrm{min}$. The correlation coefficient $\left(R^{2}>0.999\right)$ for the linear plots is very close to 1 , indicating that kinetic adsorption can be described very well using pseudo-second-order kinetics equation.

3.2.5. Effect of $\mathrm{HCO}_{3}{ }^{-}$. In nature, there is a complex chemical environment in water, in which a variety of anions and cations can be found. Among them, the competition among similar type of ions, such as $\mathrm{OH}^{-}, \mathrm{HCO}_{3}{ }^{-}, \mathrm{Cl}^{-}, \mathrm{CO}_{3}{ }^{2-}$, and $\mathrm{SO}_{4}{ }^{2-}$, has a great influence on the removal of contaminant ions by 


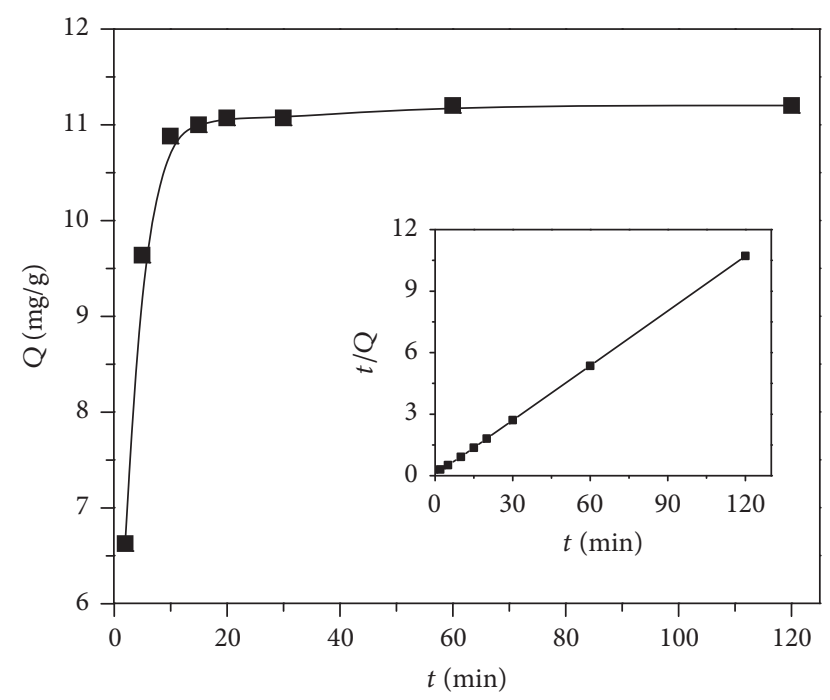

Figure 7: Effect of time on the adsorption capacities (conditions: initial concentration of solution, $12 \mathrm{mg} / \mathrm{L}$; amount of adsorbent, $1.0 \mathrm{~g} / \mathrm{L} ; \mathrm{pH}=6)$.

chemical methods. For the removal of fluoride ions, $\mathrm{OH}^{-}$ and $\mathrm{HCO}_{3}{ }^{-}$have great influence because $\mathrm{OH}^{-}$is more active than $\mathrm{F}^{-}$[54]. Therefore, $\mathrm{OH}^{-}$has the greatest impact on the removal of $\mathrm{F}^{-}$. The influence of $\mathrm{HCO}_{3}{ }^{-}$has two main aspects: one is the competition with itself and the other is the hydrolysis of $\mathrm{HCO}_{3}{ }^{-}$, which can produce $\mathrm{OH}^{-}$and affect the removal efficiency of $\mathrm{F}^{-}$. To avoid the effects of $\mathrm{OH}^{-}$, the $\mathrm{pH}$ of the solution was adjusted to 6.0. In this study, the effects of $\mathrm{HCO}_{3}{ }^{-}$on the adsorption efficiency were also investigated. By adding $1.0 \mathrm{~g} / \mathrm{L}$ of adsorbent to $3.0 \mathrm{mg} / \mathrm{L}$ of initial concentration of $\mathrm{F}^{-}$solution, the $\mathrm{pH}$ of the solution was adjusted to 6.0 , and the solution was shaken for $24 \mathrm{~h}$. The final results are shown in Figure 8. The removal efficiency was $84 \%$ when there was no $\mathrm{HCO}_{3}{ }^{-}$in the solution. On the other hand, the removal efficiency decreased sharply to $40 \%$ when there was $50 \mathrm{mg} / \mathrm{L} \mathrm{HCO}_{3}{ }^{-}$in solution. The removal efficiency decreased with increasing $\mathrm{HCO}_{3}{ }^{-}$concentration.

3.2.6. Study of Real Water Samples. The real water samples from Yuefang, Jiangji, and Sanyi were used to check the application of the product. First, the $\mathrm{pH}$ of the real water samples was adjusted to 6.0 , and $1 \mathrm{~g} / \mathrm{L}$ of Ce-bpdc was then added. Table 2 lists all the experimental data; the initial concentrations of $\mathrm{F}^{-}$in the real water samples from Yuefang, Jiangji, and Sanyi were 3.69, 3.69, and $3.83 \mathrm{mg} / \mathrm{L}$, respectively. After the reaction with Ce-bpdc for $24 \mathrm{~h}$, the concentration of $\mathrm{F}^{-}$in the real water samples from Yuefang, Jiangji, and Sanyi decreased to $0.86,1.29$, and $1.88 \mathrm{mg} / \mathrm{L}$, respectively, giving corresponding removal efficiencies of $78 \%, 64 \%$, and $50 \%$. Therefore, Ce-bpdc has high practical value in the removal of fluoride ions from real water samples.

\section{Conclusions}

Ce-bpdc, a novel type of metal organic framework, was synthesized by a facile simple chemical method. This study
TABLE 2: Treatment of real water samples by Ce-bpdc.

\begin{tabular}{lcc}
\hline Places & Before treatment $(\mathrm{mg} / \mathrm{L})$ & After treatment $(\mathrm{mg} / \mathrm{L})$ \\
\hline Yuefang & 3.69 & 0.86 \\
Jiangji & 3.69 & 1.29 \\
Sanyi & 3.83 & 1.88 \\
\hline
\end{tabular}

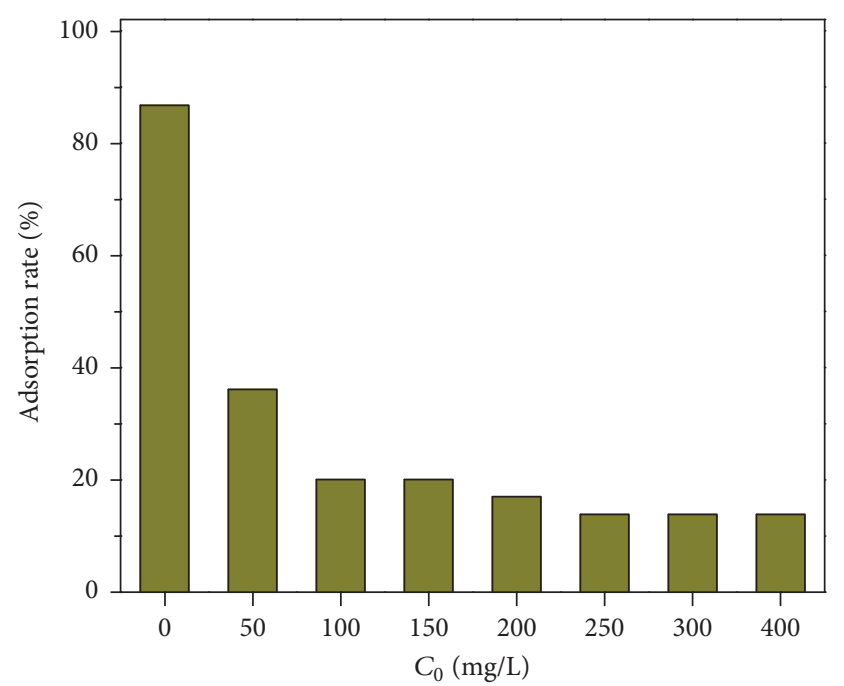

FIGURE 8: Effect of $\mathrm{HCO}_{3}{ }^{-}$on the adsorption efficiency (conditions: adsorption time, $24 \mathrm{~h}$; initial concentration of $\mathrm{F}^{-}, 3 \mathrm{mg} / \mathrm{L}$; amount of adsorbent, $1.0 \mathrm{~g} / \mathrm{L} ; \mathrm{pH}=6$ ).

investigated these factors affecting fluoride adsorption onto Ce-bpdc, including coexisting bicarbonate anions, $\mathrm{pH}$ value of fluoride solution, and contact time. The Langmuir isotherm mode fitted the equilibrium data well, and the maximum adsorption capacity was up to $45.5 \mathrm{mg} / \mathrm{g}$ for fluoride at $298 \mathrm{~K}$ and natural $\mathrm{pH}(6.0)$, and the removal efficiency was greater than $80 \%$. The adsorption of $\mathrm{F}^{-}$was mainly due to chemical adsorption with physical adsorption as a complement. The tested results of ground water samples from three places, Yuefang, Jiangji, and Sanyi which exhibited high removal efficiency, indicated that the Ce-bpdc could be effectively employed as a promising defluoridating agent.

\section{Conflicts of Interest}

The authors declare that they have no conflicts of interest.

\section{Authors' Contributions}

Changqing Zhao and Yanwei Cui equally contributed to this work as co-first authors.

\section{Acknowledgments}

This study was supported by the National Natural Science Foundation of China (Project no. 61203212). 


\section{References}

[1] P. Miretzky and A. Fernandez-Cirelli, "Fluoride removal from water by chitosan derivatives and composites: a review," Journal of Fluorine Chemistry, vol. 132, no. 4, pp. 231-240, 2011.

[2] S. Dong and Y. Wang, "Characterization and adsorption properties of a lanthanum-loaded magnetic cationic hydrogel composite for fluoride removal," Water Research, vol. 88, pp. 852-860, 2016.

[3] B.-S. Zhu, Y. Jia, Z. Jin et al., "Controlled synthesis of natroalunite microtubes and spheres with excellent fluoride removal performance," Chemical Engineering Journal, vol. 271, pp. 240251, 2015.

[4] S. Wu, K. Zhang, J. He et al., "High efficient removal of fluoride from aqueous solution by a novel hydroxyl aluminum oxalate adsorbent," Journal of Colloid and Interface Science, vol. 464, pp. 238-245, 2016.

[5] X. Zhao, P. Zhang, Y. Wang, J. Xiong, and B. Tao, "Decomposition and oriented growth of $\mathrm{YBa}_{2} \mathrm{Cu}_{3} \mathrm{O}_{7-x}$ films prepared with low fluorine TFA-MOD approach," Advances in Condensed Matter Physics, vol. 2013, Article ID 532181, 5 pages, 2013.

[6] B. Kebede, A. Beyene, F. Fufa, M. Megersa, and M. Behm, "Experimental evaluation of sorptive removal of fluoride from drinking water using iron ore," Applied Water Science, vol. 6, no. 1, pp. 57-65, 2016.

[7] W. Tang, P. Kovalsky, D. He, and T. D. Waite, "Fluoride and nitrate removal from brackish groundwaters by batch-mode capacitive deionization," Water Research, vol. 84, pp. 342-349, 2015.

[8] P. S. Ghosal and A. K. Gupta, "Enhanced efficiency of ANN using non-linear regression for modeling adsorptive removal of fluoride by calcined Ca-Al- $\left(\mathrm{NO}_{3}\right)-\mathrm{LDH}$," Journal of Molecular Liquids, vol. 222, pp. 564-570, 2016.

[9] Q. Liu, L. Zhang, B. Yang, and R. Huang, "Removal of fluoride from aqueous solution using $\mathrm{Zr}(\mathrm{IV})$ immobilized cross-linked chitosan," International Journal of Biological Macromolecules, vol. 77, pp. 15-23, 2015.

[10] A. Bhatnagar, E. Kumar, and M. Sillanpää, "Fluoride removal from water by adsorption-a review," Chemical Engineering Journal, vol. 171, no. 3, pp. 811-840, 2011.

[11] Y. Fan, D. Fu, S. Zhou et al., "Facile synthesis of goethite anchored regenerated graphene oxide nanocomposite and its application in the removal of fluoride from drinking water," Desalination and Water Treatment, vol. 57, no. 58, pp. 2839328404, 2016.

[12] S. V. Jadhav, E. Bringas, G. D. Yadav, V. K. Rathod, I. Ortiz, and K. V. Marathe, "Arsenic and fluoride contaminated groundwaters: a review of current technologies for contaminants removal," Journal of Environmental Management, vol. 162, pp. 306-325, 2015.

[13] A. Fakhri, "Application of response surface methodology to optimize the process variables for fluoride ion removal using maghemite nanoparticles," Journal of Saudi Chemical Society, vol. 18, no. 4, pp. 340-347, 2014.

[14] S. Meenakshi and N. Viswanathan, "Identification of selective ion-exchange resin for fluoride sorption," Journal of Colloid and Interface Science, vol. 308, no. 2, pp. 438-450, 2007.

[15] K. Vaaramaa and J. Lehto, "Removal of metals and anions from drinking water by ion exchange," Desalination, vol. 155 , no. 2 , pp. 157-170, 2003.

[16] L. Gómez-Hortigüela, A. B. Pinar, J. Pérez-Pariente, T. Sani, Y. Chebude, and I. Díaz, "Ion-exchange in natural zeolite stilbite and significance in defluoridation ability," Microporous and Mesoporous Materials, vol. 193, pp. 93-102, 2014.

[17] I. Bejaoui, A. Mnif, and B. Hamrouni, "Performance of reverse osmosis and nanofiltration in the removal of fluoride from model water and metal packaging industrial effluent," Separation Science and Technology, vol. 49, no. 8, pp. 1135-1145, 2014.

[18] J. Shen and A. Schäfer, "Removal of fluoride and uranium by nanofiltration and reverse osmosis: a review," Chemosphere, vol. 117, no. 1, pp. 679-691, 2014.

[19] M. B. S. Ali, B. Hamrouni, and M. Dhahbi, "Electrodialytic defluoridation of brackish water: effect of process parameters and water characteristics," Clean - Soil, Air, Water, vol. 38, no. 7, pp. 623-629, 2010.

[20] P. Sehn, "Fluoride removal with extra low energy reverse osmosis membranes: three years of large scale field experience in Finland," Desalination, vol. 223, no. 1-3, pp. 73-84, 2008.

[21] H. M. Huang, J. H. Liu, P. Zhang, D. D. Zhang, and F. M. Gao, "Investigation on the simultaneous removal of fluoride, ammonia nitrogen and phosphate from semiconductor wastewater using chemical precipitation," Chemical Engineering Journal, vol. 307, pp. 696-706, 2017.

[22] A. Dhillon, S. Prasad, and D. Kumar, "Recent advances and spectroscopic perspectives in fluoride removal," Applied Spectroscopy Reviews, vol. 52, no. 3, pp. 175-230, 2016.

[23] J. He, X. Cai, K. Chen et al., "Performance of a novelly-defined zirconium metal-organic frameworks adsorption membrane in fluoride removal," Journal of Colloid and Interface Science, vol. 484, pp. 162-172, 2016.

[24] A. Boubakri, R. Bouchrit, A. Hafiane, and S. Al-Tahar Bouguecha, "Fluoride removal from aqueous solution by direct contact membrane distillation: theoretical and experimental studies," Environmental Science and Pollution Research, vol. 21, no. 17, pp. 10493-10501, 2014.

[25] Y. Xue, K. Yang, and J. Mei, "Study of influence factor of fluorine removal from fluorinated water using coagulating sedimentation method," Engineering Journal of Wuhan University, vol. 43, pp. 477-493, 2010.

[26] H. Z. Zhao, B. Zhao, W. Yang, and T. H. Li, "Effects of $\mathrm{Ca}^{2+}$ and $\mathrm{Mg}^{2+}$ on defluoridation in the electrocoagulation process," Environmental Science and Technology, vol. 44, no. 23, pp. 91129116, 2010.

[27] R. Sinha, S. Mathur, and U. Brighu, "Aluminium removal from water after defluoridation with the electrocoagulation process," Environmental Technology, vol. 36, no. 21, pp. 2724-2731, 2015.

[28] E. W. Wambu, W. O. Ambusso, C. Onindo, and G. K. Muthakia, "Review of fluoride removal from water by adsorption using soil adsorbents - an evaluation of the status," Journal of Water Reuse and Desalination, vol. 6, no. 1, pp. 1-29, 2016.

[29] Y. Duan, C. C. Wang, X. D. Li, and W. Xu, "Fluoride adsorption properties of three modified forms of activated alumina in drinking water," Journal of Water \& Health, vol. 12, no. 4, pp. 715-721, 2014.

[30] A. Goswami and M. K. Purkait, "Kinetic and equilibrium study for the fluoride adsorption using pyrophyllite," Separation Science and Technology, vol. 46, no. 11, pp. 1797-1807, 2011.

[31] S. S. Tripathy, J.-L. Bersillon, and K. Gopal, "Removal of fluoride from drinking water by adsorption onto alum-impregnated activated alumina," Separation and Purification Technology, vol. 50, no. 3, pp. 310-317, 2006.

[32] E. Vences-Alvarez, L. H. Velazquez-Jimenez, L. F. Chazaro-Ruiz, P. E. Diaz-Flores, and J. R. Rangel-Mendez, "Fluoride removal 
in water by a hybrid adsorbent lanthanum-carbon," Journal of Colloid and Interface Science, vol. 455, pp. 194-202, 2015.

[33] H. Paudyal, B. Pangeni, K. Inoue et al., "Adsorptive removal of fluoride from aqueous solution using orange waste loaded with multi-valent metal ions," Journal of Hazardous Materials, vol. 192, no. 2, pp. 676-682, 2011.

[34] M. Mouelhi, I. Marzouk, and B. Hamrouni, "Optimization studies for water defluoridation by adsorption: application of a design of experiments," Desalination and Water Treatment, vol. 57, no. 21, pp. 9889-9899, 2016.

[35] N. A. Salem and S. M. Ebrahim Yakoot, "Adsorption kinetic and mechanism studies of thorium on nitric acid oxidized activated carbon," Desalination and Water Treatment, vol. 57, no. 58, pp. 28313-28322, 2016.

[36] L.-X. Li, D. Xu, X.-Q. Li, W.-C. Liu, and Y. Jia, "Excellent fluoride removal properties of porous hollow MgO microspheres," New Journal of Chemistry, vol. 38, no. 11, pp. 5445-5452, 2014.

[37] K. Parashar, N. Ballav, S. Debnath, K. Pillay, and A. Maity, "Rapid and efficient removal of fluoride ions from aqueous solution using a polypyrrole coated hydrous tin oxide nanocomposite," Journal of Colloid and Interface Science, vol. 476, pp. 103-118, 2016.

[38] Z. Jin, Y. Jia, K.-S. Zhang et al., "Effective removal of fluoride by porous $\mathrm{MgO}$ nanoplates and its adsorption mechanism," Journal of Alloys and Compounds, vol. 675, pp. 292-300, 2016.

[39] R. Sun, H.-B. Zhang, J. Qu, H. Yao, J. Yao, and Z.-Z. Yu, "Supercritical carbon dioxide fluid assisted synthesis of hierarchical AlOOH@reduced graphene oxide hybrids for efficient removal of fluoride ions," Chemical Engineering Journal, vol. 292, pp. 174$182,2016$.

[40] G. Demirkalp, S. Alamut, O. Arara, U. Yuksel, and M. Yuksel, "Removal of fluoride from water by $\mathrm{Al}(\mathrm{III})$-loaded and $\mathrm{Al}(\mathrm{OH})_{3}$-coated chelating resin," Desalination and Water Treatment, vol. 57, no. 11, pp. 15910-15919, 2015.

[41] C. Yang, J. Xiong, J. Wei, J. Wu, B. Zhang, and X. Luo, "High performance enhancement-mode AlGaN/GaN MIS-HEMT with selective fluorine treatment," Advances in Condensed Matter Physics, vol. 2015, Article ID 267680, 7 pages, 2015.

[42] J. Li, Q. Liu, R. Huang, and G. Wang, "Synthesis of a novel $\mathrm{Ce}(\mathrm{III})$-incorporated cross-linked chitosan and its effective removal of fluoride from aqueous solution," Journal of Rare Earths, vol. 34, no. 10, pp. 1053-1061, 2016.

[43] T. Hang, W. Zhang, H.-Y. Ye, and R.-G. Xiong, "Metal-organic complex ferroelectrics," Chemical Society Reviews, vol. 40, no. 7, pp. 3577-3598, 2011.

[44] S. Naeimi and H. Faghihian, "Performance of novel adsorbent prepared by magnetic metal-organic framework (MOF) modified by potassium nickel hexacyanoferrate for removal of $\mathrm{Cs}^{+}$ from aqueous solution," Separation and Purification Technology, vol. 175, pp. 255-265, 2017.

[45] Y. Y. Xiong, J. Q. Li, L. L. Gong et al., "Using MOF-74 for $\mathrm{Hg}^{2+}$ removal from ultra-low concentration aqueous solution," Journal of Solid State Chemistry, vol. 246, pp. 16-22, 2017.

[46] F. Ke, L.-G. Qiu, Y.-P. Yuan et al., "Thiol-functionalization of metal-organic framework by a facile coordination-based postsynthetic strategy and enhanced removal of $\mathrm{Hg}^{2+}$ from water," Journal of Hazardous Materials, vol. 196, pp. 36-43, 2011.

[47] C. Li, Z. Xiong, J. Zhang, and C. Wu, "The strengthening role of the amino group in metal-organic framework MIL-53 (Al) for methylene blue and malachite green dye adsorption," Journal of Chemical and Engineering Data, vol. 60, no. 11, pp. 3414-3422, 2015.
[48] L. Li, J. C. Li, Z. Rao, G. W. Song, and B. Hu, "Metal organic framework $\left[\mathrm{Cu}_{3}(\mathrm{BTC})_{2}\left(\mathrm{H}_{2} \mathrm{O}\right)_{3}\right]$ for the adsorption of methylene blue from aqueous solution," Desalination and Water Treatment, vol. 52, no. 37-39, pp. 7332-7338, 2014.

[49] K.-Y. A. Lin, Y.-T. Liu, and S.-Y. Chen, "Adsorption of fluoride to $\mathrm{UiO}-66-\mathrm{NH}_{2}$ in water: stability, kinetic, isotherm and thermodynamic studies," Journal of Colloid and Interface Science, vol. 461, no. 37-39, pp. 79-87, 2016.

[50] F. Ke, G. Luo, P. Chen et al., "Porous metal-organic frameworks adsorbents as a potential platform for defluoridation of water," Journal of Porous Materials, vol. 23, no. 4, pp. 1065-1073, 2016.

[51] S. Zhang, Y. Lü, X. Lin, Y. Zhang, and X. Su, "Performance and mechanisms of fluoride removal from groundwater by lanthanum-aluminum-loaded hydrothermal palygorskite composite," Chemical Research in Chinese Universities, vol. 31, no. 1, pp. 144-148, 2015.

[52] Y. Guo, T. Jia, C. Li, Y. Niu, S. Hou, and S. Liu, “Theoretical investigation on structural and electronic properties of InN growth on Ce-stabilized zirconia (111) substrates," Advances in Condensed Matter Physics, vol. 2016, Article ID 9435387, 7 pages, 2016.

[53] S. Hokkanen, A. Bhatnagar, and M. Sillanpää, "A review on modification methods to cellulose-based adsorbents to improve adsorption capacity," Water Research, vol. 91, pp. 156-173, 2016.

[54] Y.-X. Zhang and Y. Jia, "Preparation of porous alumina hollow spheres as an adsorbent for fluoride removal from water with low aluminum residual," Ceramics International, vol. 42, no. 15, pp. 17472-17481, 2016. 

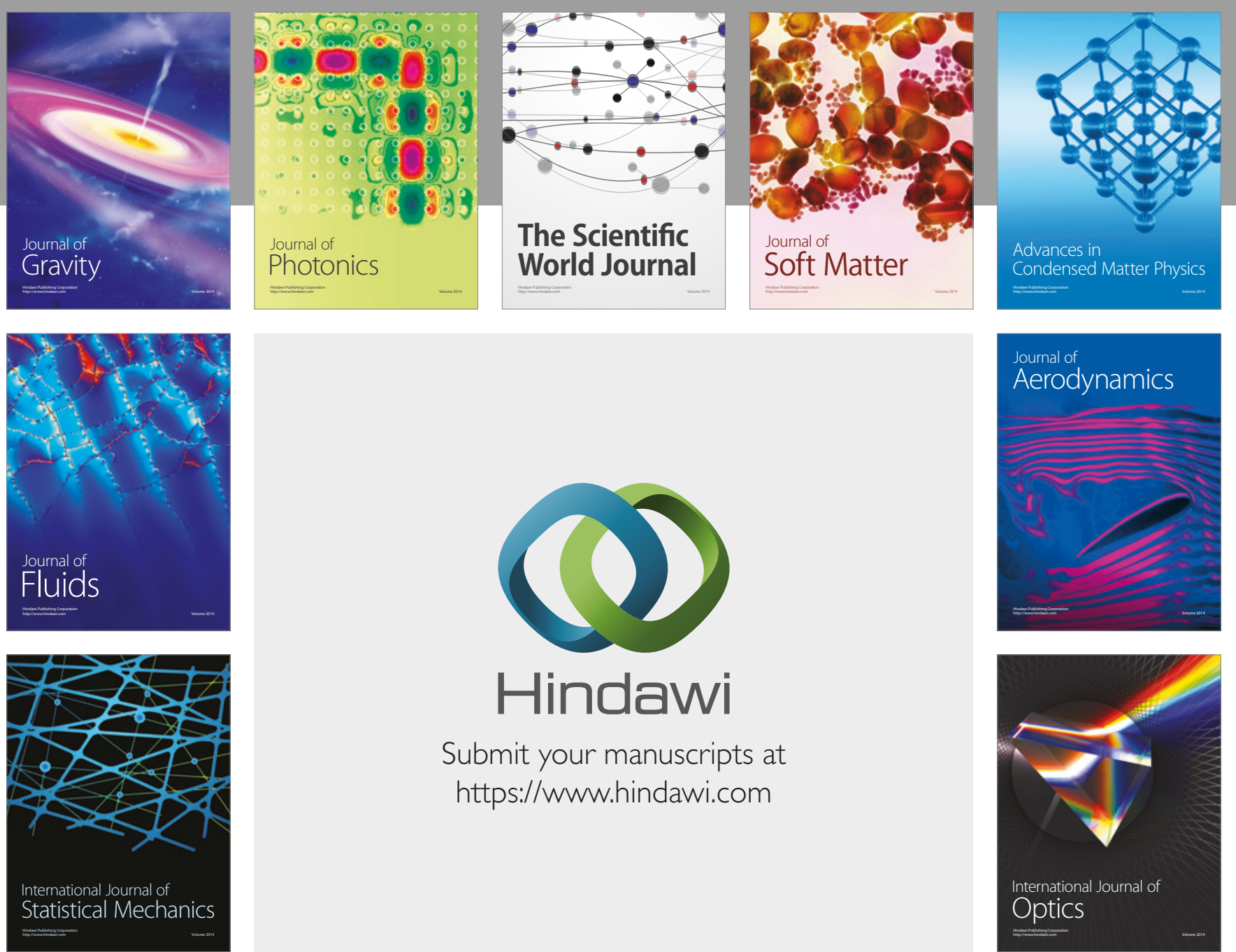

Submit your manuscripts at

https://www.hindawi.com
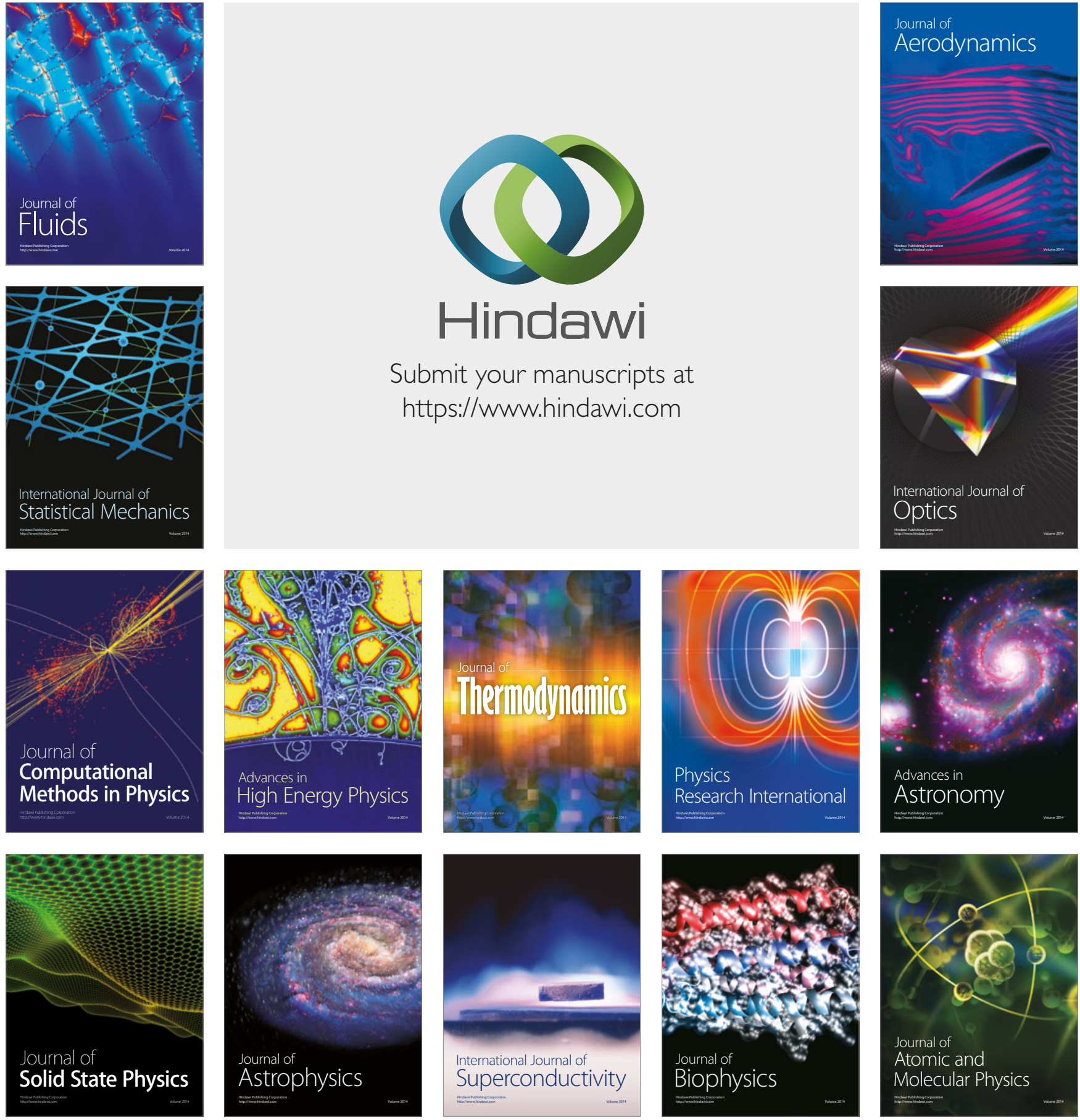